\title{
Desafios na definição e medição da legibilidade, sob o ponto de vista do Design da Informação
}

Challenges in defining and measuring legibility, under Information Design perspective

tipografia, legibilidade, receitas médicas

\begin{abstract}
O conceito da legibilidade está cercado de confusão e ambiguidade. Isso gera todo tipo de problema, incluindo brechas na interpretação da legislação brasileira sobre como devem ser feitas as receitas médicas. A lei diz que é proibido ao médico fazer receitas ilegíveis. Mas mesmo entre os estudiosos não há consenso sobre o que é algo "legível". A definição desse termo ainda é polêmica e usa palavras subjetivas como "fácil", "diferente" e "acostumado", que não deixam claro o seu significado. Mas não é só a definição de legibilidade que sofre de inconsistência. Muitas pesquisas que tentaram mensurá-la de forma objetiva também tem provocado debate, pois sofrem pela falta de validade ecológica, ou seja, seus resultados não se aplicam em condições reais de leitura. Logo, a palavra "legível", usada na legislação de saúde, não é clara o suficiente para evitar confusão e não ajuda os médicos a avaliarem se suas receitas se enquadram dentro do esperado, para garantir a segurança dos pacientes.
\end{abstract}

typography, legibility, medical prescriptions

The concept of legibility is surrounded by confusion and ambiguity. This creates all sorts of problems, including gaps in the interpretation of Brazilian law, concerning medical prescriptions. The law says it is forbidden to write illegible prescriptions. But even among scholars there is no consensus on what is "legible". The definition of this term is still controversial and uses subjective words like "easy", "different" and "familiar", obscuring its meaning. But the definition of legibility is not the only one that suffers from inconsistency. Many studies that tried to measure it from an objective perspective also has provoked debate since they lack ecological validity, that is, their results do not apply in real conditions of reading. Therefore, the word "legible", used in health legislation, is not clear enough to avoid confusion and doesn't help doctors to assess if their prescriptions fall within the expected, keeping patients safe.

\section{Introdução}

O Design da Informação é a área do conhecimento que lida com a transferência de dados complexos para representações que visam comunicar, documentar ou preservar o conhecimento. Ele busca tornar compreensíveis conjuntos inteiros de fatos e suas inter-relações, com o objetivo de criar transparência e eliminar a incerteza (Schuller, 2007). No entanto, embora o Design da Informação procure combater a dúvida, um dos seus princípios mais utilizados está cercado de confusão e ambiguidade. Esse conceito é a legibilidade tipográfica.

O uso do termo "legível" é prática comum entre produtores e leitores de textos. Muitos defendem a importância de um texto "legível" para que ele possa ser compreendido, e existem até leis que condenam letras "ilegíveis", e procuram evitar sua ocorrência, nos casos onde a comunicação deve ser clara e sem margem para dúvida.

A preocupação com a leitura clara dos textos é legítima. A falta de entendimento de um texto pode até trazer danos à saúde, como no caso de uma receita médica ambígua que leva à administração incorreta de um medicamento, trazendo danos ao paciente. Visando diminuir a ocorrência desse tipo de problema, o artigo 35, da Lei 5.991, de 1973, no item "a", determina que somente "será aviada a receita que estiver escrita a tinta, em vernáculo por extenso e de modo legível" (Brasil, 1973). O Código de Ética Médica, editado pela Resolução $n^{\circ} 1.246 / 88$ do Conselho Federal de Medicina, no Capítulo III da Responsabilidade Profissional, artigo 39, ressalta que é proibido ao médico fazer receitas ilegíveis, obscuras e incompletas (França, 1994).

Mas, determinar que as receitas médicas sejam "legíveis", sem definir o que significa este termo ou qual o parâmetro que define o grau de legibilidade adequada, não ajuda o médico a tornar sua 


\title{
Infadesıgn
}

prescrição mais compreensível.

\section{Falta de consenso na definição de "legibilidade"}

\author{
Mesmo entre os estudiosos não há consenso sobre o que é algo "legível". A definição de \\ legibilidade ainda é polêmica, com muitos conceitos diferentes (Lund, 1999). Se, entre designers \\ da informação, é difícil definir com precisão o que é legível, espera-se que entre leigos não seja \\ muito diferente.
}

Os primeiros estudos de legibilidade foram realizados no final do século 19 por Jean Anisson, sendo que objeto de preocupação de tipógrafos e designers gráficos por mais de 100 anos (Schriver, 1997).

Dentre as definições que foram dadas pra legibilidade, Tinker (1963) afirmou que ela se refere à "percepção de letras e palavras, e a leitura de material textual contínuo". Ele ainda disse que as formas das letras precisavam ser discriminadas, as formas características das palavras deviam ser percebidas e o texto contínuo deveria ser lido de modo preciso, rápido, fácil e com entendimento. Mas, mesmo ele, especialista em estudos da leitura, usou o termo "leiturabilidade", em estudos anteriores, para definir o que depois ele chamaria de legibilidade.

Aldrich e Fennell (1991) afirmam que um texto legível é aquele que é suficientemente grande e diferente para que o leitor discrimine entre palavras individuais e letras. Já um texto "readable", é aquele que pode ser lido facilmente, de modo convidativo e prazeiroso para os olhos. O texto pode ser legível, mas se o leitor ficar entediado e cansado, o designer não terá obtido a máxima leiturabilidade (readability).

Zuzana Licko argumenta ainda que legibilidade tem a ver com o hábito ou seja, que as pessoas lêem melhor e mais rápido aquilo que estão acostumadas a ler. Se a forma das letras é muito excêntrica mas as pessoas tem o hábito de ler essa forma, a legibilidade não é afetada. Com isso, defende a idéia de que não importa quão complexa seja o tipo de letra, é apenas uma questão de tempo até que nos acostumemos com ela e então se torne "legível" (Emigre, 1990).

Já Gribbons (1993) diz que a legibilidade é definida segundo 3 critérios: velocidade de leitura, fadiga visual e o nível de compreensão. Ele ainda separa a definição em dois tipos: legibilidade fisiológica (habilidade do leitor em perceber e decodificar um tipo de estilo de letra) e legibilidade estrutural (o uso da tipografia para comunicar a estrutura da informação).

Logo, para uns, um texto legível é aquele que é lido de modo preciso, rápido, fácil e com entendimento. Para outros é o texto suficientemente grande e diferente para que o leitor discrimine entre palavras individuais e letras. Ou, ainda, pode ser o texto que as pessoas estão acostumadas a ler. Só que "fácil", "diferente" e "acostumado" são termos ambíguos e subjetivos para construir uma definição que sirva de critério para a avaliação da leitura efetiva.

\section{Falta de validade ecológica e interna na medição da "legibilidade"} Mas não é só a definição de legibilidade que sofre de consistência. As pesquisas que tentaram
mensurá-la de forma objetiva também tem provocado debate.

Conforme Kinross (1992) aponta, muitas pesquisas sobre tipografia sofrem pela falta de validade ecológica, ou seja, seus resultados não se aplicam em condições reais de leitura. Muitas das pesquisas feitas se baseavam no reconhecimento de letras isoladas, ao invés da inclusão em palavras ou em passagens de texto. Ou então, estudavam um fator tipográfico, sem perceber como ele se relacionava com outros dentro do contexto (Kinross, 1992; Schriver, 1997; Lund, 1999; Arditi e Cho, 2005). O único contexto que interessava era saber se havia luz suficiente na sala para ver as formas das letras.

O mais prolífico pesquisador sobre legibilidade tipográfica foi Miles Tinker, da Universidade de Minnesota, junto com seu colega Donald Paterson, que publicaram dezenas de experimentos sobre legibilidade, além de dois livros: "Legibility of print" (1963) e "Bases for effective reading" (1965).

As pesquisas de Tinker (1963) usavam diferentes técnicas para medir o desempenho da leitura, como: velocidade de percepção, perceptibilidade à distância, perceptibilidade na visão periférica, visibilidade, piscada reflexo, fadiga na leitura e rastreamento do movimentos dos olhos. No entanto, suas pesquisas receberam diversas críticas. Dentre as falhas apontadas, estão o uso de um modelo de pesquisa univariável, falta de relação entre as conclusões e os dados levantados, e 
falta de indicação do contexto em que as recomendações se aplicam (Waller, 1987).

Parte das fraquezas levantadas nas pesquisas sobre legibilidade tipográfica, está no uso que foi feito de diferentes técnicas de coleta de dados. A seguir são feitas algumas considerações sobre a validade de alguns desses métodos.

\subsection{Velocidade de percepção}

Essa é uma técnica de exposição rápida que mostra a rapidez e precisão com a qual letras ou palavras podem ser diferenciadas. O método usado para esse experimento consiste em um campo de exposição que contém o texto impresso. Este texto é mostrado durante um período de $1 / 10$ segundos aproximadamente. $O$ tempo total pode ser reduzido visando testar o limite de reconhecimento de símbolos gráficos (Tinker, 1963). O problema desse método está em avaliar os fatores visuais de forma isolada. Como a visão é um processo ativo, que depende da coordenação entre olhos e cérebro (Barry, 1997), fica difícil afirmar que a velocidade é de percepção ou de processamento cognitivo. Ele avalia os fatores visuais de maneira isolada, independente do contexto, e isso desconsidera a característica multi-fatorial que afeta o processo de leitura.

\subsection{Perceptibilidade à distância}

Esse método procura determinar a distância máxima com que os olhos detectam símbolos gráficos. Serve para testar o reconhecimento relativo de símbolos impressos e o papel que a silhueta das palavras desempenha nesse processo. Seu uso geralmente é associado com o teste de placas de sinalização, que devem ser vistas de longe. O experimento consiste no movimento de um carro que corre sobre trilhos, de 10 em 10 centímetros. Em cada ponto, o participante lê o que for possível e faz anotações, e o movimento é repetido com distâncias cada vez mais curtas, até o momento em que conseguir ler tudo. Outra opção é manter o material de leitura parado e fazer um observador caminhar em direção ao texto, até que consiga ler perfeitamente o conteúdo (Tinker, 1963). Esse tipo de pesquisa tem potencial para a presença de problemas de validade ecológica.

\subsection{Perceptibilidade na visão periférica}

Essa experiência busca medir a distância horizontal entre um ponto de fixação e outro ponto onde um símbolo possa ser reconhecido com precisão. Uma técnica alternativa consiste no uso de um variador focal, que testa os limites nos quais uma letra pode ser desfocada e ainda ser reconhecida (Tinker, 1963). Assim como a técnica de perceptibilidade à distância, também pode apresentar resultados que não refletem condições reais de uso, comprometendo sua validade. A falta de preocupação de Tinker em pesquisar a legibilidade em situações do dia-a-dia, pode vir do fato dele ser psicólogo sem uma bagagem teórica e prática de tipografia (Waller, 1987).

\subsection{Visibilidade}

A visibilidade do texto é medida com um medidor de visibilidade Luckiesh-Moss, que consiste num tipo de fotômetro com dois filtros de densidade variável, em forma de discos (um para cada olho), que são ajustados de modo que o objeto visto através deles seja pouco discernível. Os discos são girados até que os textos sejam reconhecidos. Nesse teste tenta-se medir a legibilidade de tipos, negrito e diferentes graus de contraste figura-fundo (Tinker, 1963). Esse método é questionável, na medida em que a "leitura" pode estar se baseando na informação "não-visual" (Smith, 2003). O conteúdo previamente conhecido ou a experiência da pessoa pode modificar a maneira como parece "ver a informação" (Britton e Glynn, 1987; Hoffrage, Hertwig et al., 2000; Harley, Carlsen et al., 2004).

\subsection{Velocidade de trabalho}

Nesse tipo de experimento, procura-se medir a velocidade de leitura, em quanto tempo uma pessoa consegue encontrar um número de telefone, qual a quantidade de texto que é lida num intervalo de tempo ou qual a demora para se encontrar um número dentro de uma tabela (Tinker, 1963). De todos os testes, esse é o mais próximo do que se poderia considerar ideal, por possuir maior validade ecológica, avaliando o efeito dos aspectos tipográficos em situações reais.

\subsection{Rastreamento do movimento dos olhos (eye-tracking)}

Esse método consiste em registrar o movimento que os olhos fazem ao percorrer um texto. Durante a leitura, os olhos se movem em pequenos saltos, chamados de "sacádicos". Nos pontos onde os olhos se fixam, a visão é nítida, e é onde ocorre a percepção do material lido. Quando uma parte do texto não é entendida, os olhos executam um movimento de regressão, para reexaminar o conteúdo. A detecção do movimento pode ser feita através da reflexão da córnea, 


\section{Infodesıgn}

por gravação eletrônica (captura do ângulo de rotação dos olhos), dentre outros. Tinker (1963) fez a maior parte das suas experiências usando esse método de rastreamento, mas existem motivos para contestá-lo. O primeiro é que uma maior velocidade de leitura não significa necessariamente que um conteúdo está sendo bem compreendido. O segundo é que nem sempre a velocidade de leitura é realmente importante, em alguns casos, um prolongamento do tempo de leitura é até desejável (Britton e Glynn, 1987).

\section{Conclusão}

Muito embora não haja consenso sobre o que seja legibilidade ou mesmo como deve ser medida, os pesquisadores concordam que as características tipográficas devem ser ajustadas com responsabilidade e que elas são interdependentes ou seja, são relacionadas entre si. Dentre as características que afetam o sucesso da leitura estão: o interesse pelo texto, o conhecimento prévio da informação, a forma das letras, o tamanho das letras, a largura da linha, o espaço entre palavras, entre letras, entre linhas, o layout da página, o contraste figura fundo, a qualidade de impressão, dentre outros (Wrolstad, 1970).

Nesse contexto, o formato das letras dos médicos seria apenas um dos fatores que afetam a efetividade da leitura de uma receita médica. Além disso, a qualidade das letras são um fator periférico no processo de leitura. Outros fatores como a "velocidade de pensamento", que é um fator cognitivo, tem mais importância na leitura do que apenas o formato das letras e sua distintividade (Carver, 1992). Wright pensa o mesmo, quando diz que os processos de informação ligados à informação sensorial na página impressa, são dominados por níveis de análise mais altos, conceituais e interpretativos (Wright, 1978).

No que se refere ao design da informação, a indefinição do termo "legível" e a falta de parâmetros que permitam descrever o quão legível um texto é, comprometem as pesquisas que utilizam este conceito.

No caso das receitas médicas, essa falta de definição torna inútil a legislação que obriga médicos a escreverem de forma "legível" e clara, já que, do ponto de vista dos médicos, legível é aquilo que "pode ser lido". Como eles sempre conseguem ler a própria letra, então sua letra se encaixa na exigência da legislação médica.

Quando a legislação diz que o texto da receita médica deve ser "legível", ela ignora o fato de que a compreensão é dependente de uma série de fatores importantes como as experiências prévias de quem lê, a qualidade linguística, o processo de confecção da receita, o contexto de leitura, a estética, a credibilidade do médico, o valor de leitura, a leiturabilidade (incluindo estrutura da receita, retórica gráfica, aspectos perceptivos), dentre outros.

Apontar a legibilidade como único fator importante, para garantir o cumprimento da ordem prescritiva, torna a legislação hermética, uma caixa-preta, que não ajuda os médicos a avaliarem se sua prática se enquadra dentro do esperado e do necessário, para garantir a segurança dos pacientes no sistema de saúde.

\section{Referências}

ALDRICH-RUENZEL, N. e J. FENNELL, Eds. Designer's Guide to Typography. New York: WatsonGuptill Publicationsed. 1991.

ARDITI, A. e J. CHO. Serifs and font legibility. Vision Research, v.45, n.2005. 2005.

Barry, A. Visual Inteligence: Perception, Image and Manipulation in Visual Communication. Albany: State University of New York. 1997

BRASIL. Ministério da Saúde. Lei n 5991, de 17 de dezembro de 1973. Estabelece o controle sanitário do comércio de drogas, medicamentos, insumos farmacêuticos e correlatos. Diário Oficial da República Federativa do Brasil, Brasília, 19 dez. 1973.

BRITTON, B. e S. GLYNN, Eds. Executive Control Processes in Reading. London: Lawrence Erlbaum Associatesed. 1987.

CARVER, R. Reading rate: theory, research, and practical implications. Journal of Reading, v.36, n.2. 1992. 
França, G. Comentário ao código de ética médica. Rio de Janeiro: Guanabara Koogan. 1994. 175 p.

GRIBBONS, W. Information Design: A Human Factors Approach to A New Typography. International Professional Communication Conference, 1993. p.

HARLEY, E. M., K. A. CARLSEN, et al. The" Saw-It-All-Along" Effect: Demonstrations of Visual Hindsight Bias. Journal of Experimental Psychology Learning Memory and Cognition, v. 30, n.5, p.960-968. 2004.

HOFFRAGE, U., R. HERTWIG, et al. Hindsight Bias: A By-Product of Knowledge Updating? Journal of Experimental Psychology Learning Memory and Cognition, v.26, n.3, p.566-581. 2000.

Interview with Zuzana Licko. Emigre, n.15. 1990.

Kinross, R. Modern typography: An essay in critical theory. London: Hyphen Press. 1992

LUND, O. Knowledge Construction in Typography: the Case of Legibility Research and the Legibility of Sans Serif Typefaces. Teses de doutorado não-publicada, Department of Typography \& Graphic Communication, The University of Reading. 1999.

Schriver, K. A. Dynamics in document design: John Wiley \& Sons. 1997

SCHULLER, G. (2007). Information Design = Complexity + Interdisciplinarity + Experiment. Acessado em Out 2008, a partir de http://www.aiga.org/content.cfm/complexity-plusinterdisciplinarity-plus-experiment.

SMITH, F. Compreendendo a leitura. Porto Alegre: Artes Médicas. 2003

TINKER, M. A. Legibility of print: lowa State University Press, Ames. 1963

TINKER, M. Bases for Effective Reading. 1965

WALLER, R. The Typographic Contribution to Language. Unpublished PhD Dissertation, Department of Typography and Graphic Communication, University of Reading. 1987.

WRIGHT, P. Feeding the information eaters: suggestions for integrating pure and applied research on language comprehension. Instructional Science, v.7. 1978.

WROLSTAD, M. Methods of research into legibility and intelligibility. In: J. Dreyfus e R. Murat (Ed.). Typographic Opportunities in the Computer Age. Prague: Typografia, 1970. p.36-41.

\section{Sobre o autor}

Ricardo Martins, mestrando em Design pela Universidade Federal do Paraná. Graduado em Desenho Industrial pela mesma instituição, com habilitação em Programação Visual. Atua como professor na UFPR, no Bacharelado em Design Gráfico. No momento desenvolve pesquisas sobre a aplicação do Design da Informação na solução de problemas relacionados ao uso racional de medicamentos. E-mail: ralexm@terra.com.br 